\title{
FIRST OBSERVATIONS ON DIET AND FEEDING STRATEGY OF BOARFISH, CAPROS APER (ACTINOPTERYGII: PERCIFORMES: CAPROIDAE), IN THE EASTERN IONIAN SEA (CENTRAL MEDITERRANEAN)
}

\author{
Aikaterini ANASTASOPOULOU*, Michele TORRE, and Chryssi MYTILINEOU \\ Hellenic Centre for Marine Research, Institute of Marine Biological Resources and Inland Waters, Anavissos, \\ Attica, Greece
}

Anastasopoulou A., Torre M., Mytilineou C. 2018. First observations on diet and feeding strategy of boarfish, Capros aper (Actinopterygii: Perciformes: Caproidae), in the eastern Ionian Sea (central Mediterranean). Acta Ichthyol. Piscat. 48 (1): 99-103|.

\begin{abstract}
The presently reported study provides first and preliminary information on the feeding strategy and diet of boarfish, Capros aper (Linnaeus, 1758), in the eastern Ionian Sea (central Mediterranean). The sampling was carried out using the oceanographic RV PHILIA at the mean depth of $165 \mathrm{~m}$ in October 2014. A total of 95 C. aper were studied. The total length of the fish ranged from 4.1 to $10.3 \mathrm{~cm}$. From the total number of stomachs examined only $2.1 \%$ were empty. The fullness index (RI) did not differ between juvenile and adult individuals. Cumulative prey curve showed that the sample sizes were adequate to describe the diet of the species. Capros aper fed mainly on Crustacea, especially Copepoda, followed by Amphipoda, Malacostraca, and Tanaidacea. Prey abundance and prey frequency values did not differ between juvenile and adult individuals. The determined feeding strategy showed that the most important prey taxon (Copepoda) had been eaten by more than half of the fish, but their contribution to the gut contents of these fishes was low, indicating a generalized feeding strategy with a high within-phenotype contribution to the niche width for this prey.
\end{abstract}

Keywords: boarfish, feeding ecology, Ionian Sea, prey composition, prey importance

The boarfish, Capros aper (Linnaeus, 1758), is a Fock et al. 2002), south-eastern North Atlantic (Lopes nektonic shoaling species with a pan-Atlantic distribution. It is common throughout the Mediterranean and eastern coasts of the USA (Carpentieri et al. 2016, Froese and Pauly 2017). Given its usual high abundance, boarfish represents a significant fraction of the total bycatch of the commercial bottom trawl fishery (Tsagarakis et al. 2015). The species had been considered an unwanted catch item since 2007 where an important industrial fishery was developed primarily in ICES areas (Farrell et al. 2012 and references therein). However, the ecological role of boarfish is largely unknown. Lopes et al. (2006) supported the idea that $C$. aper has an important position in the marine food web being eaten by several other species, including birds, Calonectris diomedea; and fishes: Galeorhinus galeus (Linnaeus, 1758); Prionace glauca (Linnaeus, 1758); Phycis phycis (Linnaeus, 1766); Conger conger (Linnaeus, 1758); Xiphias gladius Linnaeus, 1758.

The diet of $C$. aper has been studied in different areas of the Mediterranean: the western part (MacPherson 1979), Aegean Sea (Sever et al. 2013), central Tyrrhenian Sea (Carpentieri et al. 2016), and the Atlantic Ocean, including Portuguese waters (Santos and Borges 2001, et al. 2006). The diet of boarfish reported by the abovementioned authors consisted primarily of copepods, specifically Calanus helgolandicus, some mysid shrimps, and euphausiids (MacPherson 1979, Fock et al. 2002, Lopes et al. 2006). As zooplankton feeder, C. aper may have an impact on eggs and larvae of other species but this hypothesis has not be proved in a study conducted in Portuguese waters (Lopes et al. 2006) and thus its increase in abundance can affect natural mortality of commercial fish species. Capros aper has been considered an important component of some species' diets such as seabirds, sharks, bony fishes (Clarke et al. 1995, Granadeiro et al. 1998, Morato et al. 2003, Xavier et al. 2010).

The presently reported study was aimed at providing first and preliminary information on the feeding strategy and diet of Capros aper in the eastern Ionian Sea, central Mediterranean.

Samples come from one experimental haul (at a mean depth of $165 \mathrm{~m}$ )) carried out during experimental bottom trawl fishing conducted in the Eastern Ionian Sea off Corfu Island (Fig. 1) in October 2014 within the framework of the DeFishGear project (str/00010, IPA-Adriatic, Cross- 
Border Cooperation 2007-2013). Sampling was carried out with the oceanographic RV PHILIA. In total, 95 $C$. aper individuals were sampled for the dietary analyses; their size ranged between 4.1 and $10.3 \mathrm{~cm}$ total length (TL). The samples were frozen immediately after capture and examined in the laboratory where total length, TL, and gut content weight $\left(W_{\text {stom }}\right)$ were determined when possible using an electronic balance of high accuracy (0.0001 g). Gut contents were analysed with a stereomicroscope to identify prey items, which were counted and weighed. Prey items were identified to the lowest possible taxonomic level. Empty guts with unidentifiable (digested) material were excluded from the analysis.

A cumulative prey curve was calculated to determine if the number of examined individuals was enough to precisely describe the diet (Ferry and Cailliet 1996).

The proportions of empty and non-empty stomachs (vacuity index, VI) were estimated as a percentage of the total number of stomachs examined. Stomach fullness was calculated using gut content weight as a percentage of $C$. aper body weight (repletion index RI). Two size groups were chosen in order to separate juveniles and adults of $C$. aper. This selection was based on Yapic1 and Filiz (2014), which estimated the females maturity size of C. aper at $6.6 \mathrm{~cm}$ TL in the Mediterranean, corresponding to 1.84 years of age. The size of the first group ranged from 4.1 to $6.4 \mathrm{~cm}$, that of the second group from 6.5 to 10.3. Statistical differences in the repletion index RI between juvenile and adult individual sizes were tested by ANOVA. Three standard indices (Hyslop 1980) were calculated to describe the presence of prey in the individuals sampled:

- Relative abundance $(\% N)$ of prey to the total number of prey items

- Percentage weight $(\% M)$ prey item in relation to the total weight of prey items

- Frequency of prey occurrence $(\% F)$

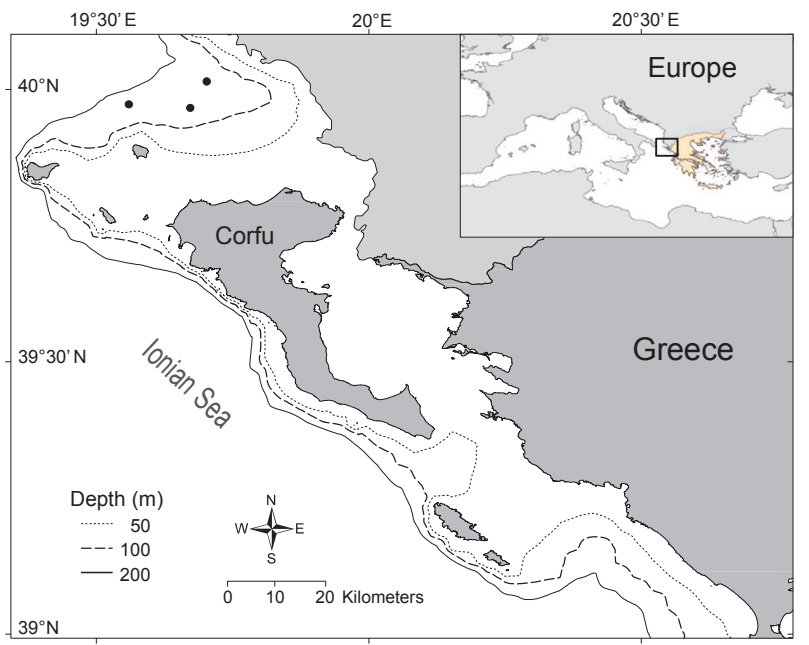

Fig. 1. Map of the study area off Corfu Island, north-eastern Ionian Sea
The importance of each prey item in the diet of $C$. aper was studied by two indices: the alimentary coefficient $(Q)$

$$
Q=\% N \times \% M
$$

and the index of relative importance IRI \%, as modified by Hacunda (1981) (and expressed as a percentage)

$$
\text { IRI }=(\% N+\% M) \times \% F
$$

According the $Q$ coefficient, prey was separated into three categories (Hureau 1970): principal for $Q>200$; secondary for $20<Q<200$, and accidental for $Q<20$. The $Q$ and IRI indices were calculated for the major prey groups. Permutational multivariate analysis of variance (PERMANOVA) was run on a Bray-Curtis similarity resemblance matrix of $(\log +1)$ transformed data for the abundance and frequency of occurrence of each major prey taxon to test if there are differences between the immature and mature individuals. The PRIMER 6 plus PERMANOVA package (Clarke and Warwick 2001, Anderson 2006) was used to perform these analyses.

Feeding strategy was represented graphically with a two-dimensional representation of prey-specific abundance $\left(P_{i}\right)$ and frequency of occurrence $(\% F)$ of the various preys. This method, based on the modified Costello graphical analysis (Amundsen et al. 1996), allows describing prey importance, feeding strategy and the inter- and intra-individual components of niche width to be explored together. Prey-specific abundance $\left(P_{i}\right)$ is defined as the percentage of a prey taxon $\left(S_{i}\right)$ contribution.

Of 95 Capros aper guts examined, 93 (98\%) contained food remains; the VI index was very low $(2 \%)$. The mean fullness index based on RI was $0.85 \%( \pm 0.06)$. However, no significant differences in the fullness index were found between juvenile and adult individuals (ANOVA, $P=0.2188, N=93, F=1.53$, $\mathrm{df}=92$ ).

Gut content analysis of the 93 individuals (4.1-10.3 $\mathrm{cm}$ TL) yielded a total of 1349 prey items, representing 19 taxa, with a total weight of $3.6 \mathrm{~g}$. Cumulative prey curve indicated that the number of guts examined was sufficient to characterize the diet of C. aper (Fig. 2). The diet indices of C. aper are shown in Table 1. Capros aper fed mainly on Crustacea and especially Copepoda, followed by Amphipoda, Malacostraca, and Tanaidacea. Other taxa were found in small proportions. The only bony fishes found in the examined guts were larvae. Platyhelminthes parasites were also found.

Analysis of both IRI and alimentary coefficient $Q$ indices (Table 1) showed that among different food items, Copepoda were the principal prey in the diet of the species $(Q=3465.84$ and IRI $=88.08 \%)$. Amphipoda were found as secondary prey in the diet of the species $(Q=52.67)$, whereas all the other prey items were classified as accidental $(Q<20)$.

PERMANOVA analysis indicated that prey abundance and prey occurrence of $C$. aper did not statistically differ between juvenile and adult individuals (PERMANOVA, abundance: $P$ (perm) $=0.467$; 
$P$ seudo $-F=0.82 ; N=93$ and occurrence: $P($ perm $)=0.828$; $P$ seudo- $F=0.12 ; N=93)$.

Feeding strategy plot (Fig. 3) showed that the most important prey (Copepoda) had been eaten by more than half of the fish, but its contribution to the gut contents was low $\left(P_{i}=14 \%\right)$, suggesting a generalized feeding strategy with a high within-phenotype contribution to the niche width. Small proportions of other prey items were present occasionally in the gut contents of some individuals.

The feeding intensity of Capros aper estimated during the presently reported study by the vacuity and repletion indices was quite low. Similar results, with the vacuity index near to zero, have been reported by Fock et al. (2002). As opposed, Sever et al. (2013) found a high degree of empty guts. Carpentieri et al. (2016) indicated that the species shows a marked daily temporal pattern, with feeding peak during daylight hours. The low vacuity index found in the presently reported work may be related to the time of sampling, which took place during daylight.

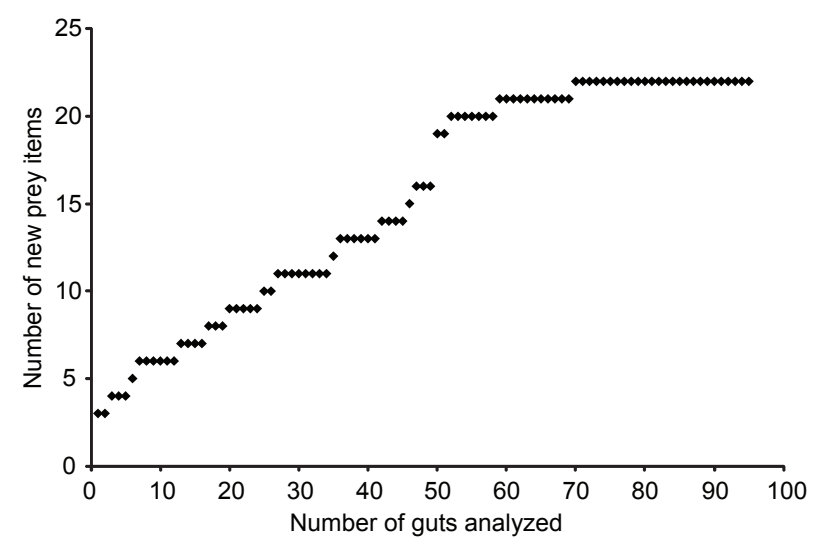

Fig. 2. Cumulative prey curve for the stomachs of Capros aper caught in the north-eastern Ionian Sea

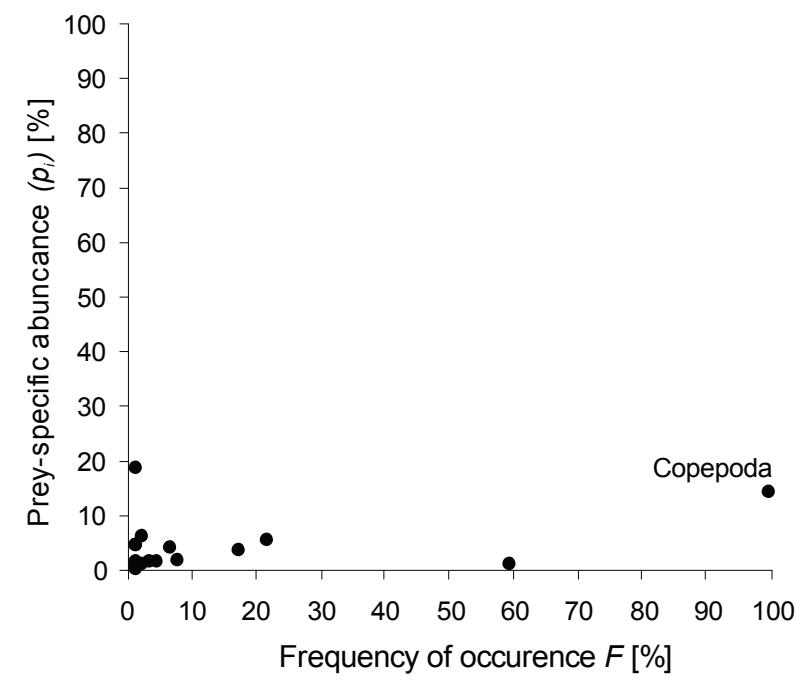

Fig. 3. Feeding strategy plot of Capros aper caught in the north-eastern Ionian Sea
The presently reported study indicated that the diet of $C$. aper in the north-eastern Ionian Sea relied mainly on Crustacea and more specifically on Copepoda. This result is generally consistent with the findings of other authors focusing on the Atlantic (Fock et al. 2002, Lopes et al. 2006), in the central Tyrrhenian Sea (Carpentieri et al. 2016), in the western Mediterranean (MacPherson 1979) and in the eastern Mediterranean (Sever et al. 2013). Santos and Borges (2001) found that Euphausiacea and Amphipoda were the main prey of $C$. aper in the southern coast of Portugal. It should be emphasized that in the presently reported work $C$. aper was found to prey on larvae of several taxa (Polychaeta, Gastropoda, Euphausiacea, Dendrobranchiata/Caridea, Brachyura, and Actinopterygii). Lopes et al. (2006), in a study conducted in Portuguese waters, did not find any correlation between boarfish abundance and the recruitment of commercial fish species, whose eggs and larvae have been preyed upon. Seasonal and daily variations in the feeding habits have been reported for this species (Fock et al. 2002, Lopes et

Table 1

Qualitative dietary composition of Capros aper in the deep waters of the north-eastern Ionian Sea

\begin{tabular}{|c|c|c|c|c|}
\hline Prey taxa & $\% N$ & $\% M$ & $\mathrm{Q}$ & $\%$ IRI \\
\hline \multicolumn{5}{|l|}{ Plantae } \\
\hline Angiospermae & 0.07 & 0.17 & 0.01 & 0.001 \\
\hline Plantae unidentified & 0.15 & 0.28 & 0.04 & 0.001 \\
\hline \multicolumn{5}{|l|}{ Polychaeta } \\
\hline Errantia & 0.15 & 0.43 & 0.06 & 0.001 \\
\hline Polychaeta larvae & 1.11 & 2.11 & 2.35 & 0.09 \\
\hline \multicolumn{5}{|l|}{ Mollusca } \\
\hline Bivalvia larvae & 0.44 & 0.02 & 0.01 & 0.001 \\
\hline Gastropoda larvae & 0.07 & 0.21 & 0.02 & 0.001 \\
\hline \multicolumn{5}{|l|}{ Crustacea } \\
\hline Crustacea unidentified & 0.30 & 3.38 & 1.00 & 0.07 \\
\hline Amphipoda & 10.08 & 5.22 & 52.67 & 1.49 \\
\hline Copepoda & 76.43 & 45.35 & 3465.84 & 88.08 \\
\hline Euphausiacea & 0.07 & 0.04 & 0.003 & 0.001 \\
\hline Euphausiacea larvae & 0.15 & 0.34 & 0.05 & 0.001 \\
\hline Mysida & 0.07 & 2.17 & 0.16 & 0.01 \\
\hline $\begin{array}{l}\text { Dendrobranchiata/Caridea } \\
\text { unid. }\end{array}$ & 0.15 & 1.62 & 0.24 & 0.02 \\
\hline $\begin{array}{l}\text { Dendrobranchiata/Caridea } \\
\text { larvae }\end{array}$ & 0.22 & 1.17 & 0.26 & 0.02 \\
\hline Brachyura larvae & 0.07 & 0.08 & 0.01 & 0.001 \\
\hline \multicolumn{5}{|l|}{ Malacostraca } \\
\hline Tanaidacea & 5.41 & 2.35 & 12.74 & 0.60 \\
\hline Tunicata & 0.07 & 0.38 & 0.03 & 0.001 \\
\hline \multicolumn{5}{|l|}{ Actinopterygii } \\
\hline Actinopterygii larvae & 0.89 & 3.33 & 2.96 & 0.14 \\
\hline Mucus & 4.08 & 31.36 & 127.85 & 9.46 \\
\hline No. of examined individuals & 9 & 33 & & \\
\hline \multicolumn{5}{|l|}{ Other } \\
\hline Detritus & & + & & \\
\hline Platyhelminthes parasites & - & + & & \\
\hline
\end{tabular}

$\% N=$ relative abundance, $\% M=$ percentage weight, $Q=$ alimentary coefficient, \%IRI = index of relative importance. 
al. 2006, Carpentieri et al. 2016). Carpentieri et al. (2016) noticed that copepods and amphipods showed only slight seasonal differences in comparison to the gastropods. Works conducted in different seasons (Fock et al. 2002, Lopes et al. 2006, Sever et al. 2013, Carpentieri et al. 2016, presently reported study) showed that copepods were the most important prey of the species in all cases. The high copepods abundance in the $C$. aper diet could also be related to the diurnal variability in feeding habits. Boarfish feed predominantly on copepods during the daylight from dawn to late afternoon (Fock et al. 2002, Carpentieri et al. 2016) which coincide with the zooplankton migration to deeper water layers.

According to the results of the presently reported study, the diet of Capros aper included pelagic zooplankton (i.e., Copepoda, crustacean larvae, Tunicata, fish larvae), plants, benthic invertebrates (i.e., Polychaeta, Mollusca) and hyperbenthos (i.e., Mysidacea, Euphausiacea, Amphipoda, and Decapoda). This pattern of diet may be linked to the biology of species: remaining close to the bottom, resting during the night and feeding during daylight on hyperbenthos (Carpentieri et al. 2016 and references therein). Thus, it could be suggested that $C$. aper is an active predator which forages in the water column and thereby serves as a vector of energy between pelagic and benthic ecosystems. In addition, $C$. aper holds an important position in the marine food web, being eaten by seabirds such as Calonectris diomedea (see Granadeiro et al. 1998) by sharks such as Galeorhinus galeus (see Morato et al. 2003) or Prionace glauca (see Clarke et al. 1996) and by bony fishes such as Xiphias gladius, Conger conger, and Pagellus bogaraveo (Brünnich, 1768) (see Clarke et al. 1995, Morato et al. 2003, Xavier et al. 2010).

The study of the feeding strategy of $C$. aper showed that Copepoda - the species' dominant prey-had a high frequency of occurrence that combined with their preyspecific abundance suggested a population generalized feeding behaviour with a high within-phenotype contribution to the niche width for this prey. The population is composed of generalists, each exploiting a wide range of overlapping resources (Pianka 1988).

The role of $C$. aper in food webs is still largely unknown but seems very important. This is because they consume a large quantity of the abundant meso- and macro-zooplankton. On the other hand, their resultant high biomass provides forage for organisms at higher trophic levels (e.g., seabirds, sharks). Capros aper was a discarded bycatch in the past and for this reason, little interest has been given to this species (Egerton et al. 2017). However, since 2001 it became a target of the fishery in the NE Atlantic off the South West of Ireland and from 2011 TAC was set by the Council of EU whereas long-term management plans have been proposed by the Pelagic Advisory Council (Anonymous 2016).

\section{ACKNOWLEDGMENTS}

Authors would like to thank the captain and the crew of the RV PHILIA for their help and support during the samplings and Mr J. Haralabous for this contribution on the illustrations of this work. Moreover, authors would like to thank the two anonymous reviewers for suggesting improvements to the manuscript. Authors also confirm that there is no any kind of conflict of interest. This study was supported by the DeFishGear project, IPA-Adriatic, Cross-Border Cooperation 2007-2013.

\section{REFERENCES}

Amundsen P.-A., Gabler H.-M., Staldvik F.J. 1996. A new approach to graphical analysis of feeding strategy from stomach contents data-modification of the Costello (1990) method. Journal of Fish Biology 48 (4): 607-614. DOI: 10.1111/j.1095-8649.1996.tb01455.x

Anderson M.J.2006. Distance-based tests forhomogeneity of multivariate dispersions. Biometrics 62 (1): 245 253. DOI: $10.1111 / \mathrm{j} .1541-0420.2005 .00440 . x$

Anonymous 2016. Report of the Working Group on Widely Distributed Stocks (WGWIDE). 31 August-6 September 2016, ICES HQ, Copenhagen, Denmark. ICES CM 2016/ACOM:16

Carpentieri P., Serpetti N., Colloca F., Criscoli A., Ardizzone G. 2016. Food preferences and rhythms of feeding activity of two co-existing demersal fish, the longspine snipefish, Macroramphosus scolopax (Linnaeus, 1758), and the boarfish Capros aper (Linnaeus, 1758), on the Mediterranean deep shelf. Marine Ecology 37 (1): 106-118. DOI: 10.1111/ maec. 12265

Clarke M.R., Clarke D.C., Martins H.R., Da Silva H.M. 1995. The diet of the swordfish (Xiphias gladius) in Azorean waters. Arquipélago-Life and Marine Sciences 13A: 53-69.

Clarke M.R., Clarke D.C., Martins H.R., Da Silva H.M. 1996. The diet of the blue shark (Prionace glauca L.) in Azorean waters. Arquipélago-Life and Marine Sciences 14A: 41-56.

Clarke K.R., Warwick R.M. 2001. Change in marine communities: An approach to statistical analysis and interpretation. Pp. 176. PRIMER E, Second Edition, Plymouth, UK.

Egerton S., Culloty S., Whooley J., Stanton C., Ross R.P. 2017. Boarfish (Capros aper): Review of a new capture fishery and its valorization potential. ICES Journal of Marine Science 74 (8): 2059-2068. DOI: $10.1093 /$ icesjms/fsx048

Farrell E., Hüssy K., Coad J.O., Causen L.W., Clarke M.W. 2012. Oocyte development and maturity classification of boarfish (Capros aper) in the Northeast Atlantic. ICES Journal of Marine Science 69 (4): 498-507. DOI: 10.1093/icesjms/fss037

Ferry L.A., Cailliet G.M. 1996. Sample size and data analysis: Are we characterizing and comparing diet properly? Pp. 71-80. In: MacKinaly D., Shearer K. (eds.) "Gutshop '96" Feeding Ecology and Nutrition in Fish Symposium Proceedings, International Congress on the Biology of Fishes, 14-16 July 1996, San Francisco State University, San Francisco, California, USA. American Fisheries Society, Physiology Section. 
Fock H.O., Matthiessen B., Zidowitz H., von Westenhagen H. 2002. Diel and habitat-dependent resource utilisation by deep-sea fishes at the Great Meteor Seamount: Niche overlap and support for the sound scattering layer interception hypothesis. Marine Ecology Progress Series 244: 219-233. DOI: 10.3354/ meps 244219

Froese R., Pauly D. (eds.) 2017. FishBase. [Version 10/2017] www.fishbase.org

Granadeiro J.P., Monteiro L.R., Furness R.W. 1998. Diet and feeding ecology of Cory's shearwater Calonectris diomedea in the Azores, north-east Atlantic. Marine Ecology Progress Series 166: 267276. DOI: $10.3354 /$ meps 166267

Hacunda J.S. 1981. Trophic relationships among demersal fishes in a coastal area of the Gulf of Maine. Fishery Bulletin 79 (4): 775-788.

Hureau J.-C. 1970. Biologie comparée de quelques poisons antarctiques (Nototheniidae). Bulletin de l'Institut océanographique de Monaco. 68 (1391): 139-164.

Hyslop E.J. 1980. Stomach contents analysis - a review of methods and their application. Journal of Fish Biology 17 (4): 411-429. DOI: 10.1111/j.10958649.1980.tb02775.x

Lopes M., Murta A.G., Cabral H.N. 2006. The ecological significance of the zooplanktivores, snipefish Macroramphosus spp. and boarfish Capros aper, in the food web of the south-east North Atlantic. Journal of Fish Biology 69 (2): 363-378. DOI: 10.1111/j.10958649.2006.01093.x

MacPherson E. 1979. Relations trophiques des poissons dans la Méditerranée occidentale. Commission Internationale pour l'Exploration Scientifique de la mer Méditerranée. Rapports et procès verbaux des réunions 25/26: 49-57.

Morato T., Solà E., Grós M.P., Menezes G. 2003. Diets of thornback ray (Raja clavata) and tope shark (Galeorhinus galeus) in the bottom longline fishery of the Azores, northeastern Atlantic. Fishery Bulletin 101 (3): 590-602.

Pianka E.R. 1988. Evolutionary ecology. 4th edn. Harper and Row, New York, NY, USA.

Santos J., Borges T. 2001. Trophic relationships in deep-water fish communities off Algarve, Portugal. Fisheries Research 51 (2-3): 337-341. DOI: 10.1016/ S0165-7836(01)00257-0

Sever T., Bayhan B., Filiz H., Taşkavak E., Bilge G. 2013. Diet composition of the five deep sea fish from the Aegean Sea. Ege Journal of Fisheries and Aquatic Sciences 30 (2): 61-67.

Tsagarakis K., Başusta A., Başusta N., Biandolino F., Bostanci D., Buz K., Djodjo Z., Dulčić J., Gökoğlu M., Gücü A.C., Machias A., Maravelias C.D., Özvarol Y., Polat N., Prato E., Vasilakopoulos P., Yedier S. 2015. New fisheries-related data from the Mediterranean (October 2015). Mediterranean Marine Science 16 (3): 703-713. DOI: 10.12681/mms.1396

Xavier J.C., Cherel Y., Assis C.A., Sendao J., Borges T.C. 2010. Feeding ecology of conger eels (Conger conger) in north-east Atlantic waters. Journal of the Marine Biological Association of the United Kingdom 90 (3): 493-501. DOI: 10.1017/S0025315409990555

Yapıcı S., Filiz H. 2014. Estimation of age, growth and reproduction of boarfish, Capros aper, in the south Aegean Sea. Pakistan Journal of Zoology 46 (4): 1061-1068.

Received: 20 October 2017

Accepted: 2 February 2018

Published electronically: 31 March 2018 